\title{
A synergistic effect of variability in estimated glomerular filtration rate with chronic kidney disease on all-cause mortality prediction in patients with type 2 diabetes: a retrospective cohort study
}

Yu-Shan Chang ${ }^{1,2}$, Yu-Hsuan Li ${ }^{1,3}$ and I-Te Lee ${ }^{1,2,4^{*}}$ (I)

\begin{abstract}
Background: The combination of diabetes mellitus (DM) and chronic kidney disease (CKD) is associated with a high risk of mortality. Annual assessment of the estimated glomerular filtration rate (eGFR) is recommended for patients with DM. We investigated the effect of variability in annual eGFR values on all-cause mortality in patients with type 2 DM.

Methods: In this retrospective cohort study, we enrolled patients with eGFR data between 01 Aug 2017 and 31 July 2018. We defined the index eGFR as the first available eGFR value within the enrollment year and collected additional annual eGFR data from the previous three years. A total of 3592 patients with type 2 DM were enrolled, including 959 patients with CKD (index eGFR $<60 \mathrm{~mL} / \mathrm{min} / 1.73 \mathrm{~m}^{2}$ ) and 2633 patients without CKD. We assessed eGFR variability by using the standard deviation (SD) of the three annual eGFR and index eGFR values. We divided patients into subgroups according to the median SD of their annual eGFR $\left(7.62 \mathrm{~mL} / \mathrm{min} / 1.73 \mathrm{~m}^{2}\right)$. The primary endpoint was all-cause mortality after the index eGFR was assessed.
\end{abstract}

Results: During a median follow-up of 19 months (interquartile range: 18-20 months), 127 (3.5\%) deaths occurred among all 3592 enrolled patients. The highest mortality risk was observed in the high SD with CKD group, with a hazard ratio (HR) of 2.382 [95\% confidence interval (Cl) 1.346-4.215] in comparison to the low SD without CKD group after adjusting for the associated factors. In patients without CKD, a high SD was an independent risk factor for mortality $(H R=2.105,95 \% \mathrm{Cl} 1.256-3.528)$. According to the $\mathrm{C}$-index, the mortality prediction ability was better for the index eGFR + SD model than for the index eGFR alone model (0.671 vs. 0.629, $P<0.001)$.

Conclusion: There was a synergistic effect of eGFR variability with single-measured eGFR for the prediction of mortality in patients with type $2 \mathrm{DM}$. The SD of the annual eGFR values was also an independent predictor of mortality in patients with an eGFR $>60 \mathrm{~mL} / \mathrm{min} / 1.73 \mathrm{~m}^{2}$.

\footnotetext{
*Correspondence: itlee@vghtc.gov.tw

${ }^{1}$ Division of Endocrinology and Metabolism, Department of Internal

Medicine, Taichung Veterans General Hospital, No. 1650, Section 4, Taiwan Boulevard, Taichung 40705, Taiwan

Full list of author information is available at the end of the article
}

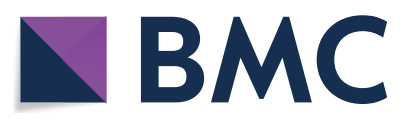

(c) The Author(s) 2021. Open Access This article is licensed under a Creative Commons Attribution 4.0 International License, which permits use, sharing, adaptation, distribution and reproduction in any medium or format, as long as you give appropriate credit to the original author(s) and the source, provide a link to the Creative Commons licence, and indicate if changes were made. The images or other third party material in this article are included in the article's Creative Commons licence, unless indicated otherwise in a credit line to the material. If material is not included in the article's Creative Commons licence and your intended use is not permitted by statutory regulation or exceeds the permitted use, you will need to obtain permission directly from the copyright holder. To view a copy of this licence, visit http://creativecommons.org/licenses/by/4.0/. The Creative Commons Public Domain Dedication waiver (http://creativeco mmons.org/publicdomain/zero/1.0/) applies to the data made available in this article, unless otherwise stated in a credit line to the data. 
Keywords: Annual, Chronic kidney disease, Estimated glomerular filtration, Mortality, Standard deviation, Type 2

diabetes, Variability

\section{Background}

Chronic kidney disease (CKD) is a critical risk factor for death [1]. According to the systematic analysis of the Global Burden of Disease Study, approximately 1.23 million people died from CKD in 2017, and the global all-age mortality rate for CKD increased by $41.5 \%$ between 1990 and 2017 [2]. The global prevalence of CKD between stages 3 and 5 was reported to be approximately 10.6\%, and diabetes mellitus (DM) is a major risk factor for CKD [3]. As the number of people with DM has been increasing worldwide [4], DM has become the most important cause of new-onset CKD [5, 6]. Type $2 \mathrm{DM}$, the major type of DM, was responsible for more than 400 thousand deaths of CKD and was reported to be the second leading cause of CKD-related death in 2019 [6].

A reduction in estimated glomerular filtration rate (eGFR), as well as the presence of albuminuria, is an independent predictor for mortality in patients with type 2 DM [7-9]. Annual assessments of eGFR and urinary albumin-to-creatinine ratio (UACR) are recommended in the clinical management of patients with DM [10-12]. In particular, the stage of CKD is recommended to be defined using the eGFR value $[13,14]$. However, a metaanalysis reported that mortality risk was not linearly correlated with eGFR in individuals with an eGFR $\geq 60 \mathrm{~mL} /$ $\mathrm{min} / 1.73 \mathrm{~m}^{2}$ [15]. An eGFR higher than the normal range might be associated with an increased risk of mortality in patients with type 2 DM [16]. Therefore, it is not sufficient to predict mortality using a single-measurement of eGFR in patients with eGFR $\geq 60 \mathrm{~mL} / \mathrm{min} / 1.73 \mathrm{~m}^{2}$, and other associated risk factors for mortality should be assessed in patients with type $2 \mathrm{DM}$ without hypofiltration [17].

Although the rate of annual eGFR assessments could be greater than $80 \%$, the rate of annual UACR assessments was less than $50 \%$ in patients with type 2 DM [18]. Similarly, based on the data of National Health Insurance in Taiwan, the rate of annual eGFR assessments was $74.2 \%$ and that of UACR was $35.9 \%$ in 2014 [19]. The variability in eGFR has been reported to be associated with new-onset DM in a Korean population and with CKD progression in the population with DM $[20,21]$. Perkins et al. [22] reported that eGFR variability could significantly predict mortality in patients with stage 3 CKD. However, a recent post hoc analysis from the ADVANCE trial reported that eGFR variability was significantly associated with the primary outcome, including major macrovascular events, new or worsening nephropathy and all-cause mortality, but eGFR variability was not significantly associated with all-cause mortality as a secondary outcome in patients with type 2 DM [23]. These inconsistent results might be explained by the various CKD stages and presence of DM in the study population. We hypothesized the existence of a synergistic effect of eGFR and previous eGFR variability on mortality prediction in patients with type $2 \mathrm{DM}$. Therefore, we conducted a retrospective cohort study to investigate the association between the standard deviation (SD) of previously measured eGFR values and mortality in type $2 \mathrm{DM}$ patients with and without CKD.

\section{Methods \\ Study design and population}

This observational cohort study was conducted in Taichung Veterans General Hospital. We retrospectively screened candidates from outpatients who had visited the Division of Endocrinology and Metabolism. The inclusion criteria were: (1) adults with type $2 \mathrm{DM}$; and (2) at least one serum creatinine level assessed between 01 Aug 2017 and 31 July 2018. We defined the index eGFR as the eGFR calculated using the first available serum creatinine level within the enrollment year. We further collected additional eGFR data from the past three years, and recorded the first-available eGFR during the annual period. We excluded patients who met any of the following conditions: (1) pregnancy, (2) the index eGFR assessed during hospitalization or in the emergency room, (3) end-stage renal disease when the index eGFR was assessed, and (4) incomplete annual eGFR data within 1 and 3 years prior to the index eGFR.

After the index eGFR was assessed, the occurrence of all-cause mortality was recorded. Information on deaths registered through August 31, 2019, was obtained from the Ministry of Health and Welfare, Executive Yuan, Taiwan. This research protocol was approved by the Institutional Review Board of Taichung Veterans General Hospital, and the need for informed consent was waived due to the retrospective cohort study design.

\section{Assessments of risk factors}

The laboratory data of hemoglobin A1c (HbA1c), total cholesterol, high-density lipoprotein (HDL) cholesterol, triglycerides, and creatinine were recorded in the enrollment year. HbA1c was measured using cation-exchange high-performance liquid chromatography (NGSP certified; G8, TOSOH, Tokyo, Japan). Serum lipid profiles 
and creatinine levels were measured by commercial kits (Beckman Coulter, Fullerton, CA, USA). The eGFR was calculated using the formula: eGFR $=186 \times$ [serum creatinine $(\mathrm{mg} / \mathrm{dL})]^{-1.154} \times[\text { age }(\text { years })]^{-0.203}(\times 0.742$ if female) based on the Modification of Diet in Renal Disease (MDRD) equation [13]. CKD was defined as an index eGFR $<60 \mathrm{~mL} / \mathrm{min} / 1.73 \mathrm{~m}^{2}$. The mean eGFR was calculated as the average of the index eGFR and other three annual eGFR values recorded within the three years prior to the index eGFR. The variability in annual eGFR was calculated using the SD of the four eGFR datasets mentioned above. Patients were divided into the high and low SD of annual eGFR groups based on the median of $7.62 \mathrm{~mL} / \mathrm{min} / 1.73 \mathrm{~m}^{2}$. Hypertension was defined as a systolic blood pressure $\geq 140 \mathrm{mmHg}$, a diastolic blood pressure $\geq 90 \mathrm{mmHg}$, or the current use of an antihypertensive drug. Obesity in Taiwan was defined as a body mass index (BMI) $\geq 27 \mathrm{~kg} / \mathrm{m}^{2}[24,25]$. Low HDL cholesterol was defined as an HDL cholesterol level $<50 \mathrm{mg} / \mathrm{dL}$ $(1.29 \mathrm{mmol} / \mathrm{L})$ in women or $<40 \mathrm{mg} / \mathrm{dL}(1.03 \mathrm{mmol} / \mathrm{L})$ in men. The UACR was calculated using the ratio of urine albumin $(\mathrm{mg} / \mathrm{dL})$ to urine creatinine $(\mathrm{g} / \mathrm{dL})$, and albuminuria was defined as a UACR $\geq 300 \mathrm{mg} / \mathrm{g}$.

\section{Statistical analysis}

Continuous data are presented as the mean \pm standard deviation; differences among the four study groups were analyzed using one-way analysis of variance, and the Scheffé test was conducted for the post hoc analysis of the differences between the paired groups. Categorical data are summarized as numbers with percentages (\%) and were compared among groups using the chi-square test. The primary endpoint was all-cause mortality.

The cumulative risk of all-cause mortality was assessed using Kaplan-Meier analysis; the log-rank test was used to determine whether the survival rates among groups were significantly different. Multivariable Cox proportional hazards regression analysis was conducted to identify the independent predictors of mortality; hazard ratio (HR) and 95\% confidence interval (CI) were calculated.

We compared the mortality prediction of the different models by examining the $\mathrm{C}$-index. The performance of the index eGFR +SD model was compared with that of the index eGFR alone model using the integrated discrimination improvement (IDI) and continuous net reclassification improvement (NRI) to quantify the improvement in predictive ability. The relationship between the annual eGFR values and time was determined by Spearman's correlation. A two-sided $\mathrm{P}$ value $<0.05$ was considered statistically significant. Statistical analysis was performed using SPSS v22.0 (IBM Corp., Armonk, NY, USA) and R software v3.4.

\section{Results}

Of the 5597 patients with type $2 \mathrm{DM}, 3592$ patients who met the study criteria were enrolled, including 2633 patients without CKD and 959 patients with CKD. Furthermore, we divided all patients into four subgroups based on the median SD of their annual eGFR. There were 1241 patients in the low SD without CKD group, 1392 patients in the high SD without CKD group, 555 patients in the low SD with CKD group, and 404 patients in the high SD with CKD group (Fig. 1).

The clinical characteristics of the enrolled patients are shown in Table 1. Among the four subgroups, there were significant differences in age $(\mathrm{P}<0.001)$, BMI $(\mathrm{P}=0.002)$, duration of $\mathrm{DM}(\mathrm{P}<0.001)$, systolic blood pressure $(\mathrm{P}<0.001)$, HbA1c $(\mathrm{P}=0.005)$, total cholesterol $(\mathrm{P}<0.001)$, HDL cholesterol $(\mathrm{P}<0.001)$, triglycerides $(\mathrm{P}<0.001)$, index eGFR $(\mathrm{P}<0.001)$, mean eGFR $(\mathrm{P}<0.001)$, SD of annual eGFR $(\mathrm{P}<0.001)$, and proportions of males $(\mathrm{P}<0.001)$, current smokers $(\mathrm{P}<0.001)$, individuals with cardiovascular disease (CVD) history $(\mathrm{P}<0.001)$, individuals with hypertension $(\mathrm{P}<0.001)$, individuals with albuminuria $(\mathrm{P}<0.001)$, individuals using angiotensin-converting enzyme (ACE) inhibitors or angiotensin II receptor antagonists $(\mathrm{ARBs})(\mathrm{P}<0.001)$, individuals using antiplatelet drugs $(\mathrm{P}<0.001)$, individuals using insulin therapy $(\mathrm{P}<0.001)$, and individuals using oral antidiabetic drugs $(\mathrm{P}=0.008)$.

Using the post hoc analyses, patients with low SD had a significantly older age $(65.0 \pm 9.8$ vs. $63.2 \pm 9.6$ years, $\mathrm{P}<0.001)$, a higher proportion of males $(62.3$ vs. $45.2 \%, \mathrm{P}<0.001)$, lower total cholesterol $(4.0 \pm 0.8$ vs. $4.1 \pm 0.9 \mathrm{mmol} / \mathrm{L}, \mathrm{P}<0.001)$, lower triglycerides $(1.4 \pm 0.8$ vs. $1.5 \pm 1.3, \mathrm{P}=0.013)$, a lower index eGFR $(84.6 \pm 16.1$ vs. $\left.93.4 \pm 21.1 \mathrm{~mL} / \mathrm{min} / 1.73 \mathrm{~m}^{2}, \quad \mathrm{P}<0.001\right)$, a lower mean eGFR $\left(85.2 \pm 15.9\right.$ vs. $97.8 \pm 20.1 \mathrm{~mL} / \mathrm{min} / 1.73 \mathrm{~m}^{2}$, $\mathrm{P}<0.001)$, a lower SD of annual eGFR $(5.0 \pm 1.6$ vs. $\left.13.7 \pm 7.1 \mathrm{~mL} / \mathrm{min} / 1.73 \mathrm{~m}^{2}, \mathrm{P}<0.001\right)$, and lower proportions of insulin use ( $19.7 \mathrm{vs.} 23.1 \%, \mathrm{P}=0.038)$ and sodium glucose cotransporter 2 (SGLT2) inhibitors use (10.6 vs. $14.6 \%, \mathrm{P}=0.003)$ in the group of patients without CKD. However, in the group of patients with CKD, the subgroup with a low SD had a significantly higher proportion of males (61.1 vs. $51.5 \%, \mathrm{P}=0.003)$, lower triglycerides $(1.6 \pm 1.3$ vs. $1.9 \pm 2.0, \mathrm{P}=0.007)$, a lower mean eGFR $\left(46.7 \pm 11.3\right.$ vs. $\left.54.7 \pm 15.0 \mathrm{~mL} / \mathrm{min} / 1.73 \mathrm{~m}^{2}, \mathrm{P}<0.001\right)$, a lower SD of annual eGFR ( $4.4 \pm 1.7$ vs. $13.6 \pm 7.2 \mathrm{~mL} /$ $\left.\min / 1.73 \mathrm{~m}^{2}, \mathrm{P}<0.001\right)$, and a lower proportion of metformin use (22.5 vs. $28.5 \%, \mathrm{P}=0.043)$ (Table 1$)$.

During a median follow-up of 19 months (interquartile range: 18-20 months), a total of 127 (3.5\%) deaths occurred among all 3592 enrolled patients. The baseline characteristics and mortality cause of expired patients are shown in the Additional file 1: Table S1. The annual 


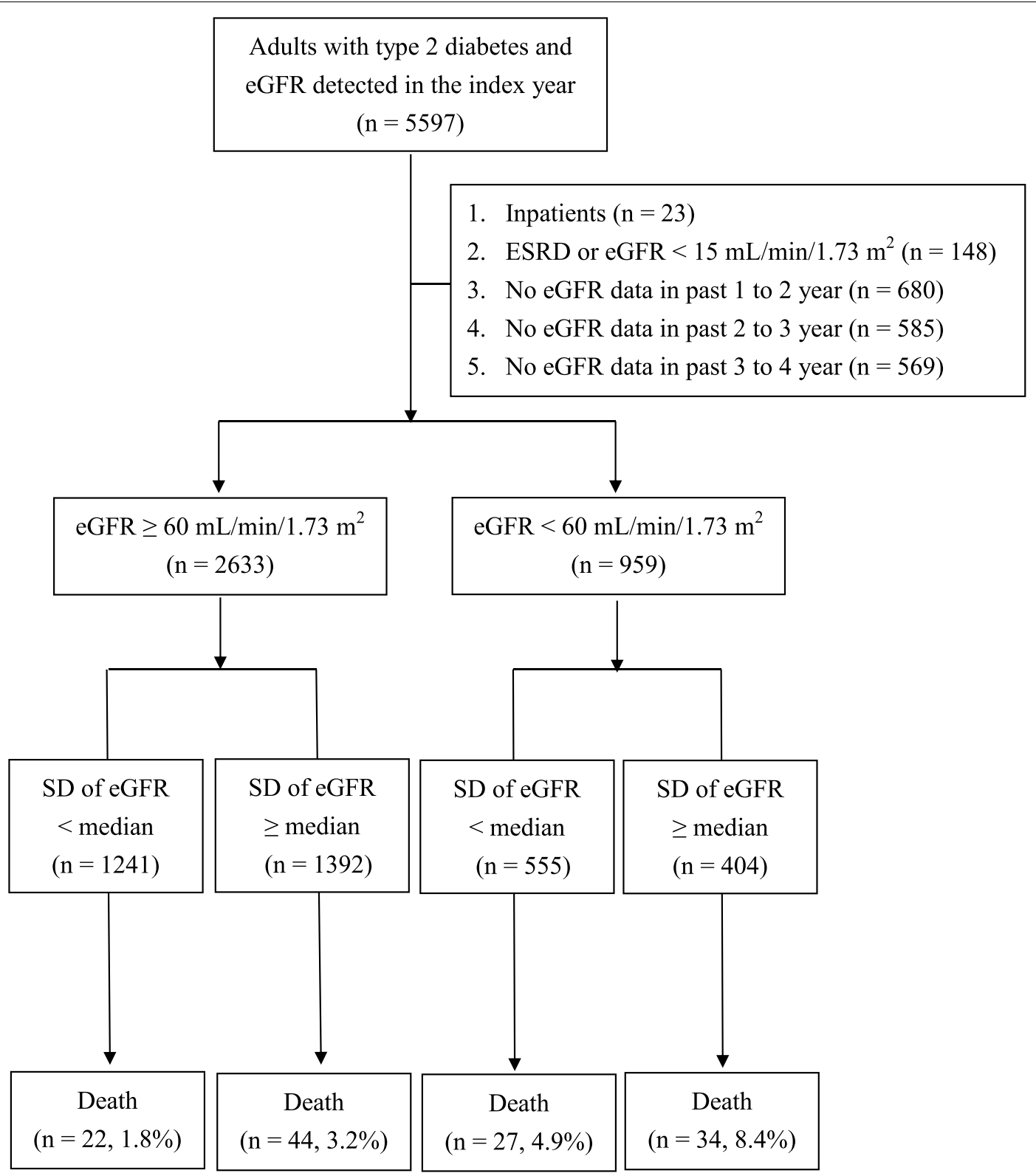

Fig. 1 Flow diagram of the enrollment of study subjects. ESRD end-stage renal disease, eGFR estimated glomerular filtration rate, SD standard deviation

incidence of mortality was 1.1 per 100 person-years in the low SD without CKD group, 2.0 per 100 person-years in the high SD without CKD group, 3.2 per 100 personyears in the low SD with CKD group, and 5.6 per 100 person-years in the high SD with CKD group. Based on the Kaplan-Meier analysis, the survival rates were significantly different among these four groups (log-rank test $\mathrm{P}<0.001$, Fig. 2). The mortality risks were still significantly different among these four groups $(P=0.003)$ after adjusting for the associated risk factors selected from Table 1 by using multivariate Cox regression analysis. Among the patients without CKD, a high SD of annual eGFR significantly predicted mortality with an HR of 2.105 (95\% CI 1.256-3.582); among the patients with a low SD of annual eGFR, however, CKD did not significantly predict mortality $(\mathrm{HR}=1.224,95 \% \mathrm{CI}$ 0.675-2.217). There was a synergistic effect of CKD and a high SD of annual eGFR on mortality prediction, with an HR of 2.382 (95\% CI 1.346-4.215) after adjusting for age, sex, current smoking status, CVD history, obesity, 
Table 1 Characteristics of the enrolled patients categorized based on CKD and SD of eGFR

\begin{tabular}{|c|c|c|c|c|c|}
\hline & \multicolumn{2}{|l|}{ CKD (-) n= 2633} & \multicolumn{2}{|l|}{ CKD $(+) N=959$} & \multirow[t]{2}{*}{$\mathbf{P}$} \\
\hline & Low SD $(n=1241)$ & High SD $(n=1392)$ & Low SD $(n=555)$ & High SD $(n=404)$ & \\
\hline Age (year) & $65.0 \pm 9.8$ & $63.2 \pm 9.6^{a}$ & $73.0 \pm 10.0^{\mathrm{ab}}$ & $71.3 \pm 10.5^{\mathrm{ab}}$ & $<0.001$ \\
\hline Male, n (\%) & $773(62.3 \%)$ & $629(45.2 \%)^{\mathrm{a}}$ & $339(61.1 \%)^{b}$ & $208(51.5 \%)^{\mathrm{abc}}$ & $<0.001$ \\
\hline Current smoking, n (\%) & $142(11.4 \%)$ & $127(9.1 \%)$ & $32(5.8 \%)^{\mathrm{ab}}$ & $25(6.2 \%)^{\mathrm{a}}$ & $<0.001$ \\
\hline CVD history, n (\%) & $155(12.5 \%)$ & $198(14.2 \%)$ & $128(23.1 \%)^{\mathrm{ab}}$ & $114(28.2 \%)^{\mathrm{ab}}$ & $<0.001$ \\
\hline $\mathrm{BMI}\left(\mathrm{kg} / \mathrm{m}^{2}\right)$ & $25.7 \pm 3.9$ & $25.8 \pm 4.4$ & $25.8 \pm 4.0$ & $26.6 \pm 4.2^{\mathrm{ab}}$ & 0.002 \\
\hline Duration of diabetes (year) & $13.2 \pm 7.6$ & $12.4 \pm 7.1$ & $17.2 \pm 8.6^{\mathrm{ab}}$ & $16.0 \pm 8.8^{\mathrm{ab}}$ & $<0.001$ \\
\hline Hypertension, n (\%) & 947 (76.3\%) & $1033(74.2 \%)$ & $521(93.9 \%)^{\mathrm{ab}}$ & $382(94.6 \%)^{\mathrm{ab}}$ & $<0.001$ \\
\hline Systolic BP (mmHg) & $135 \pm 18$ & $135 \pm 18$ & $141 \pm 19^{\mathrm{ab}}$ & $142 \pm 22^{\mathrm{ab}}$ & $<0.001$ \\
\hline Diastolic BP (mmHg) & $77 \pm 10$ & $76 \pm 11$ & $76 \pm 11$ & $76 \pm 13$ & 0.231 \\
\hline HbA1c (\%) & $7.3 \pm 1.3$ & $7.5 \pm 1.4$ & $7.4 \pm 1.4$ & $7.6 \pm 1.7^{*}$ & 0.005 \\
\hline Total cholesterol (mmol/L) & $4.0 \pm 0.8$ & $4.1 \pm 0.9^{\mathrm{a}}$ & $4.0 \pm 0.8^{b}$ & $4.0 \pm 0.9^{b}$ & $<0.001$ \\
\hline HDL cholesterol (mmol/L) & $1.3 \pm 0.4$ & $1.3 \pm 0.4$ & $1.3 \pm 0.4^{b}$ & $1.2 \pm 0.4^{\mathrm{ab}}$ & $<0.001$ \\
\hline Triglycerides (mmol/L) & $1.4 \pm 0.8$ & $1.5 \pm 1.3^{\mathrm{a}}$ & $1.6 \pm 1.3^{\mathrm{a}}$ & $1.9 \pm 2.0^{\mathrm{abc}}$ & $<0.001$ \\
\hline Index eGFR (mL/min/1.73 $\left.\mathrm{m}^{2}\right)$ & $84.6 \pm 16.1$ & $93.4 \pm 21.1^{\mathrm{a}}$ & $44.2 \pm 11.4^{\mathrm{ab}}$ & $42.9 \pm 12.3^{\mathrm{ab}}$ & $<0.001$ \\
\hline Mean of eGFR (mL/min/1.73 m²) & $85.2 \pm 15.9$ & $97.8 \pm 20.1^{\mathrm{a}}$ & $46.7 \pm 11.3^{\mathrm{ab}}$ & $54.7 \pm 15.0^{* \#+}$ & $<0.001$ \\
\hline $\mathrm{SD}$ of $\mathrm{eGFR}\left(\mathrm{mL} / \mathrm{min} / 1.73 \mathrm{~m}^{2}\right)$ & $5.0 \pm 1.6$ & $13.7 \pm 7.1^{\mathrm{a}}$ & $4.4 \pm 1.7^{b}$ & $13.6 \pm 7.2^{* \dagger}$ & $<0.001$ \\
\hline Albuminuria & $69(5.6 \%)$ & $87(6.3 \%)$ & $143(25.8 \%)^{\mathrm{ab}}$ & $117(29.0 \%)^{\mathrm{ab}}$ & $<0.001$ \\
\hline ACE inhibitor or ARB, n (\%) & $491(39.6 \%)$ & $489(35.1 \%)$ & $312(56.2 \%)^{\mathrm{ab}}$ & $223(55.2 \%)^{\mathrm{ab}}$ & $<0.001$ \\
\hline Antiplatelet, $\mathrm{n}(\%)$ & $339(27.3 \%)$ & $371(26.7 \%)$ & $243(43.8 \%)^{\mathrm{ab}}$ & $198(49.0 \%)^{\mathrm{ab}}$ & $<0.001$ \\
\hline Statins, n (\%) & 929 (74.9\%) & $1027(73.8 \%)$ & $414(74.6 \%)$ & $291(72.0 \%)$ & 0.701 \\
\hline Insulin therapy, n (\%) & $244(19.7 \%)$ & $321(23.1 \%)^{\mathrm{a}}$ & $170(30.6 \%)^{\mathrm{ab}}$ & $144(35.6 \%)^{\mathrm{ab}}$ & $<0.001$ \\
\hline Oral antidiabetic drugs & $1124(90.6 \%)$ & $1255(90.2 \%)$ & $479(86.3 \%)$ & $349(86.4 \%)$ & 0.008 \\
\hline Insulin secretagogues, n (\%) & $484(39.0 \%)$ & $519(37.3 \%)$ & $227(40.9 \%)$ & $156(38.6 \%)$ & 0.505 \\
\hline Metformin, n (\%) & $508(40.9 \%)$ & $559(40.2 \%)$ & $125(22.5 \%)^{\mathrm{ab}}$ & $115(28.5 \%)^{\mathrm{abc}}$ & $<0.001$ \\
\hline Thiazolidinediones, n (\%) & $298(24.0 \%)$ & $359(25.8 \%)$ & $143(25.8 \%)$ & $99(24.5 \%)$ & 0.721 \\
\hline DPP4 inhibitors, n (\%) & $748(60.3 \%)$ & $816(58.6 \%)$ & $349(62.9 \%)$ & $253(62.6 \%)$ & 0.251 \\
\hline SGLT2 inhibitors, n (\%) & $132(10.6 \%)$ & $203(14.6 \%)^{\mathrm{a}}$ & $28(5.0 \%)^{\mathrm{ab}}$ & $22(5.4 \%)^{\mathrm{ab}}$ & $<0.001$ \\
\hline Mortality, n (\%) & $22(1.8 \%)$ & $44(3.2 \%)^{\mathrm{a}}$ & $27(4.9 \%)^{\mathrm{a}}$ & $34(8.4 \%)^{\mathrm{abc}}$ & $<0.001$ \\
\hline $\begin{array}{l}\text { Incidence of mortality (deaths/100 } \\
\text { person-years) }\end{array}$ & 1.1 & 2.0 & 3.2 & 5.6 & $<0.001$ \\
\hline
\end{tabular}

Continuous data are presented as the mean $\pm \mathrm{SD}$, and categorical data are presented as numbers (\%)

CKD was defined as an index eGFR $<60 \mathrm{~mL} / \mathrm{min} / 1.73 \mathrm{~m}^{2}$, and SD of eGFR was grouped based on the median of $7.62 \mathrm{~mL} / \mathrm{min} / 1.73 \mathrm{~m}{ }^{2}$

$A C E$ angiotensin-converting enzyme, $A R B$ angiotensin II receptor antagonist, $B M I$ body mass index, $B P$ blood pressure, $C V D$ cardiovascular disease, $D P P 4$ dipeptidyl peptidase-4, eGFR estimated glomerular filtration rate, HbA1c hemoglobin A1c, HDL high-density lipoprotein, SD standard deviation, SGLT2 sodium glucose cotransporter 2

a -c Indicates statistically significant differences $(P<0.05)$ compared to the low SD without CKD, high SD without CKD, and low SD with CKD groups, respectively; only one of the three markers, in the order of priority, is used between the compared groups

${ }^{d}$ Using log rank test

duration of DM, hypertension, HbA1c, total cholesterol, HDL cholesterol, triglycerides, albuminuria, the use of ACE inhibitors or ARBs, and the use of statins, antiplatelet agents, insulin, metformin, and SGLT2 inhibitors (Table 2).

We generated the operating characteristic curves to differentiate all-cause mortality using the different models, including the index eGFR alone model, the mean of annual eGFR alone model, the SD of annual eGFR alone model, and the index eGFR + SD of annual
eGFR model (Fig. 3). The C-index was significantly higher for the index eGFR + SD of annual eGFR model than for the index eGFR alone model [0.671 (95\% CI $0.620-0.723$ ) vs. 0.629 (95\% CI 0.574-0.684), $\mathrm{P}<0.001]$. The C-index of the mean eGFR alone model [0.619 (95\% CI 0.566-0.673)] or that of the SD of annual eGFR alone model [0.593 (95\% CI 0.541-0.644)] was not significantly different compared with that of the index eGFR alone model ( $\mathrm{P}=0.846$ and 0.800 , respectively). To examine the superiority of the performance for the 


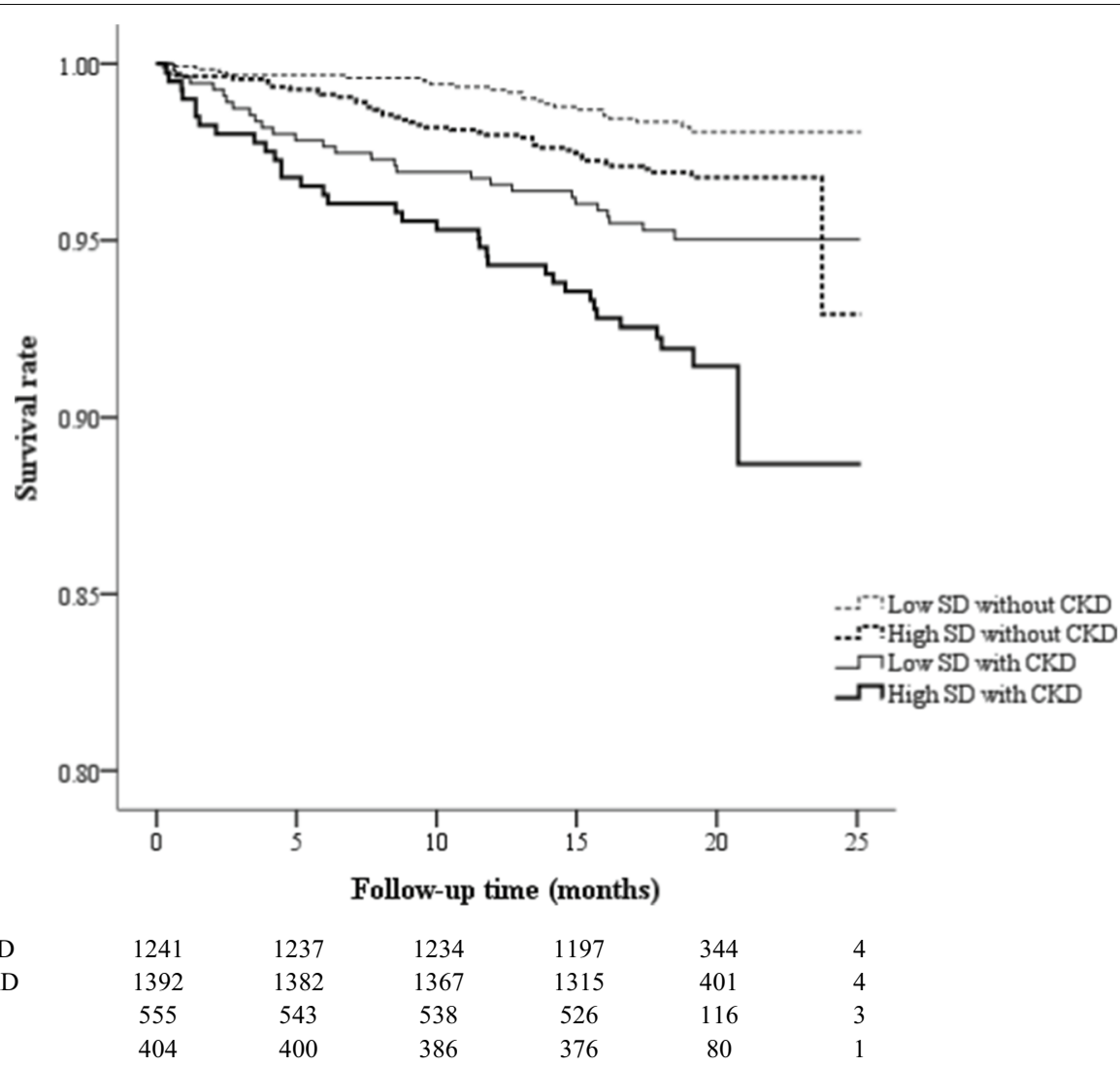

Fig. 2 Kaplan-Meier curves showing the survival rates across the four groups defined based on chronic kidney disease (CKD) and standard deviation (SD) of annual estimated glomerular filtration rate (log-rank test $\mathrm{P}<0.001$ )

prediction of mortality using the index eGFR + SD of annual eGFR model to that using the index eGFR alone model, the IDI and NRI were calculated. The model of the index eGFR + SD of annual eGFR showed a significantly better IDI of 0.008 (95\% CI $0.002-0.023)$ and NRI of 0.141 ( $95 \%$ CI $0.017-0.252$ ) than the model of index eGFR alone (Table 3).

To understand the relationship between the slopes of eGFR trajectories and mortality, we divided all patients into three groups according to the correlation between changes in eGFR and time. The patients with a positive rank coefficient of correlation were categorized as the increasing trend group $(n=1098)$, and the others were categorized into the mild decreasing group $(n=1247)$ and the obvious decreasing group $(\mathrm{n}=1247)$ based on the median of the negative coefficients. The curves of eGFR changes over time are shown in Fig. 4. The incidences of mortality were $2.0,2.3$, and 2.4 deaths/ 100 personyears in the increasing trend group, the mild decreasing group, and the obvious decreasing group, respectively. There was no significant difference in the cumulative risk of mortality among these three groups assessed using Kaplan-Meier analysis $(\log$-rank test $\mathrm{P}=0.727)$.

\section{Discussion}

The main finding in the present study is that previous variability in annual eGFR in the past 3 years had a synergistic effect with CKD for the prediction of allcause mortality in patients with type 2 DM during a median follow-up of 19 months. Furthermore, variability in annual eGFR was an independent predictor of all-cause mortality in type $2 \mathrm{DM}$ patients with an eGFR $\geq 60 \mathrm{~mL} / \mathrm{min} / 1.73 \mathrm{~m}^{2}$. In line with our findings, Al-Aly et al. [26] reported that previous variability in eGFR significantly predicted mortality in patients with an eGFR $<60 \mathrm{~mL} / \mathrm{min} / 1.73 \mathrm{~m}^{2}$. In patients with DM, Tseng et al. [21] reported that variability in eGFR significantly predicted the composite outcome of dialysis and mortality in patients with CKD, and Jun et al. [23] also reported that variability in eGFR significantly predicted the composite outcome but not mortality alone. The strength of our study is that we demonstrated that variability in eGFR has a synergistic effect with CKD on the prediction of the primary endpoint of all-cause mortality in patients with type $2 \mathrm{DM}$. In contrast to the above two studies, we retrospectively collected the SD of annual eGFR before the index eGFR. In clinical application, therefore, physicians 


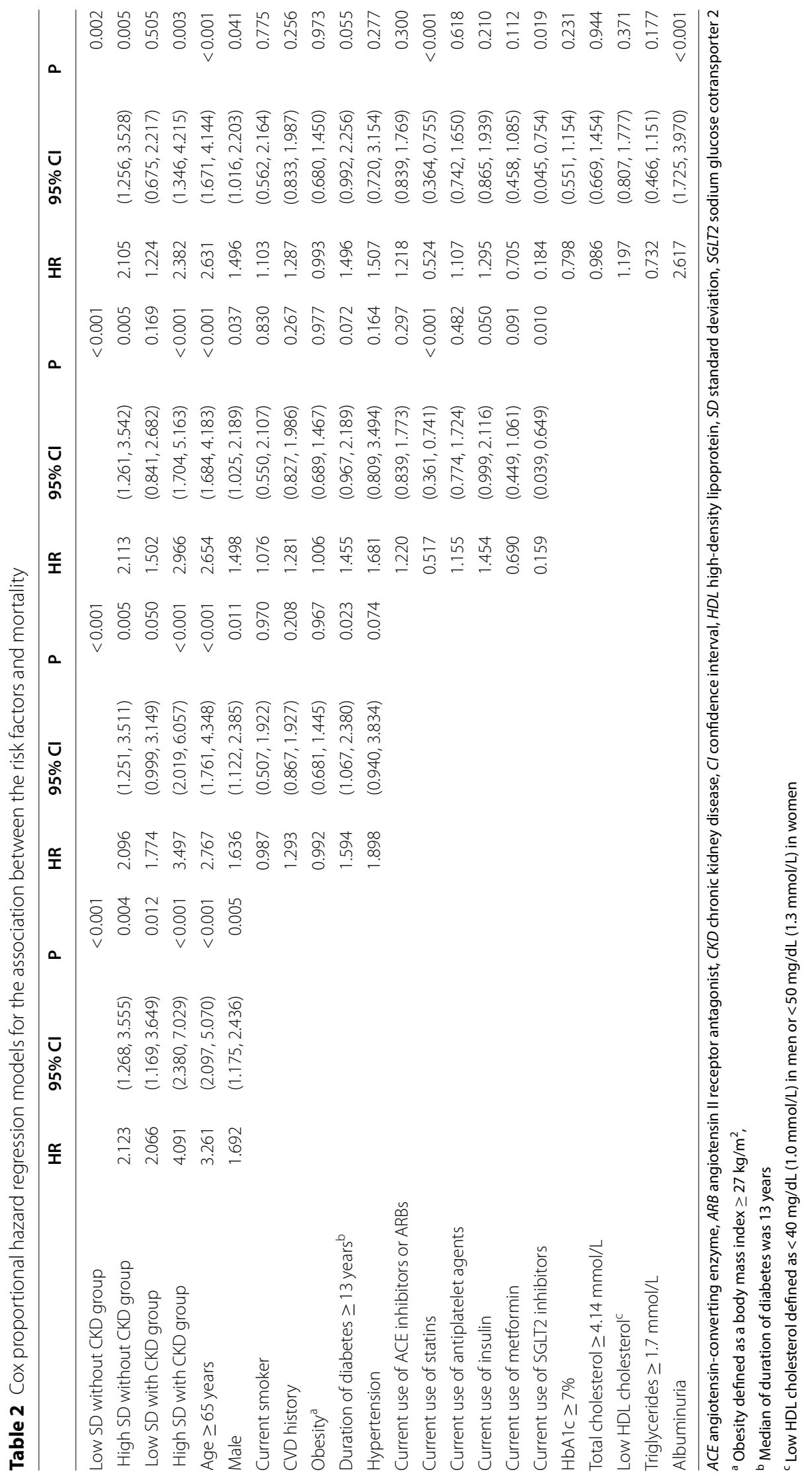




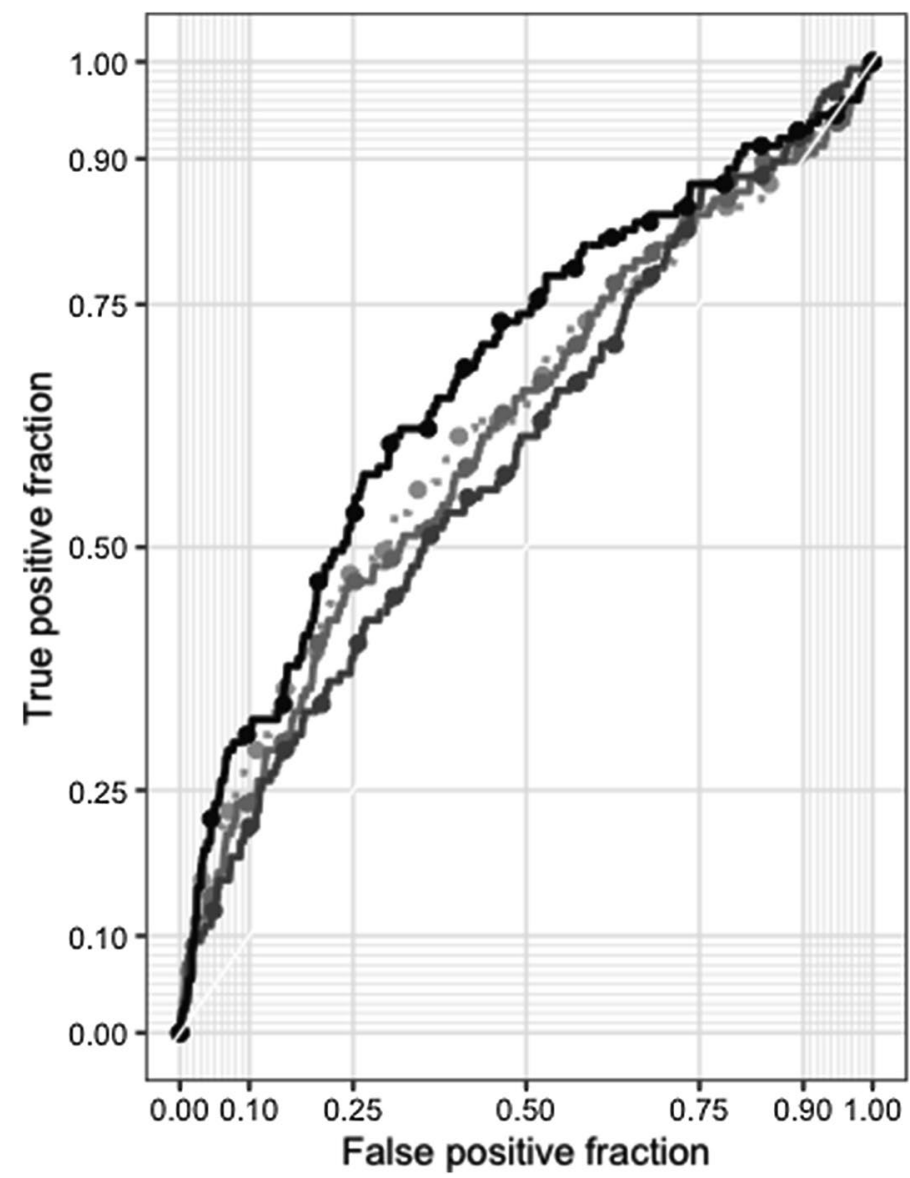

\section{- Index eGFR \\ - Mean eGFR \\ - SD of eGFR \\ $\sim \mathrm{SD}$ of eGFR+ Index eGFR}

Fig. 3 Receiver operating characteristic curves for the prediction of all-cause mortality in the index eGFR alone model, the mean of annual eGFR alone model, the SD of annual eGFR alone model, and the index eGFR + SD of annual eGFR model. eGFR estimated glomerular filtration rate, SD standard deviation

Table 3 The performance of the different models compared to the index eGFR model on the prediction of all-cause mortality

\begin{tabular}{lllllll}
\hline & C-index & P & IDI $(\mathbf{9 5 \%}$ Cl) & P & NRI (95\% CI) & P \\
\hline Index eGFR & $0.629(0.574,0.684)$ & & Reference & & Reference \\
Mean eGFR & $0.619(0.566,0.673)$ & 0.846 & $-0.003(-0.010,0.002)$ & 0.159 & $-0.155(-0.336,0.097)$ & 0.246 \\
SD of eGFR & $0.593(0.541,0.644)$ & 0.800 & $-0.008(-0.022,0.005)$ & 0.199 & $-0.154(-0.282,0.011)$ & 0.060 \\
Index eGFR + SD & $0.671(0.620,0.723)$ & $<0.001$ & $0.008(0.002,0.023)$ & 0.007 & $0.141(0.017,0.252)$
\end{tabular}

$C I$ confidence interval, IDI integrated discrimination improvement, $N R I$ continuous net reclassification improvement, eGFR estimated glomerular filtration rate, SD standard deviation

can categorize the risk of patients when enrolled if they have previous annual eGFR data.

Moreover, in the present study, we found that an SD of annual eGFR $\geq$ the median of $7.62 \mathrm{~mL} / \mathrm{min} / 1.73 \mathrm{~m}^{2}$ could significantly predict all-cause mortality in patients with an eGFR $\geq 60 \mathrm{~mL} / \mathrm{min} / 1.73 \mathrm{~m}^{2}$. Although a low index eGFR seemed to predict mortality, CKD based on the index eGFR was no longer an independent predictor for mortality after adjusting for associated factors in patients with an SD of annual eGFR $<7.62 \mathrm{~mL} / \mathrm{min} / 1.73 \mathrm{~m}^{2}$. Hyperfiltration with a high eGFR was reported to be associated with increased mortality risk in patients with type 2 DM [17], and rapid change in eGFR might be a critical risk factor for mortality in those with a high eGFR [27]. Therefore, eGFR variability plays an important role in mortality risk and might be a better predictor than 


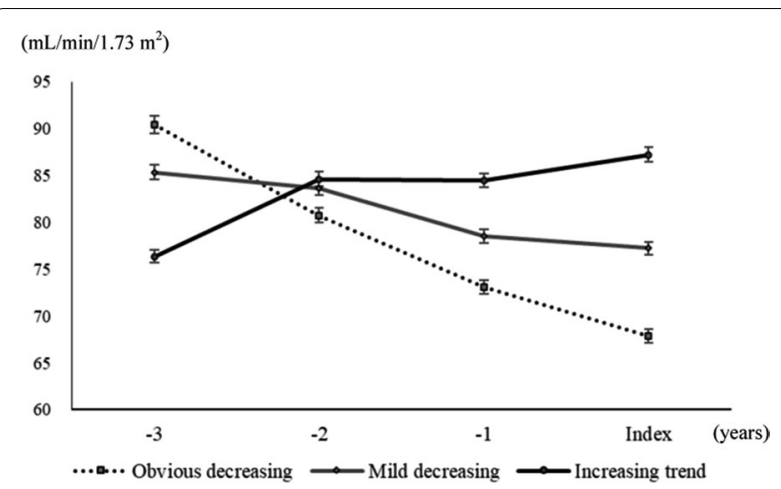

Fig. 4 The trends of eGFR change over time among the three groups categorized based on the correlation between eGFR and time. Means and standard error bars of annual eGFR are plotted for each group. eGFR estimated glomerular filtration rate

single-measured eGFR in type $2 \mathrm{DM}$ patients with an eGFR $\geq 60 \mathrm{~mL} / \mathrm{min} / 1.73 \mathrm{~m}^{2}$.

There are several possible mechanisms underlying the association between high eGFR variability and increased mortality risk. First, variability in eGFR is associated with systemic inflammatory reactions. An episode of acute kidney injury, defined as highest serum creatinine $>150 \%$ or an increment $\geq 0.3 \mathrm{mg} / \mathrm{dL}$ compared to the lowest serum creatinine during hospitalization, was reported to predict major adverse outcomes and death in patients with type 2 DM independent of their CKD stage [28]. An increase in systemic inflammatory markers was observed in the renal ischemia-reperfusion model of mice [29]. Episodes of acute kidney injury, independent of renal failure, might induce leukocyte infiltration in distant organs, which was associated with cell apoptosis and dysfunction in the renal ischemic model of rats [30]. The data of annual eGFR assessed during hospitalization or in the emergency room in the past three years could have been collected, and the probable effect of an acute systemic disease on long-term mortality could not be excluded in the present study. Second, an increase in circulating glucose might induce renal hemodynamic changes and variability in eGFR [31]. Glucose variability might also induce endothelial dysfunction and result in micro- and macrovascular diseases in patients with DM [32-35]. Therefore, the association between eGFR variability and increased mortality might result from unstable glucose control in patients with type $2 \mathrm{DM}$. Third, variability in eGFR might be reflected by active comorbidities, which are associated with long-term mortality [36]. The annual rate of eGFR decline was reported to be greater in patients with type 2 DM than in those without DM [37]. Insulin resistance might be associated with intrarenal hemodynamic dysfunction and predictive of all-cause mortality in patients with type $2 \mathrm{DM}[38,39]$. Diabetic retinopathy was reported to be associated with eGFR variability and predictive of all-cause mortality in patients with type 2 DM [40, 41]. Peripheral artery disease (PAD) was also reported to be associated with CKD [42], and a high-risk PAD is predictive of all-cause mortality in patients with type 2 DM [43]. Moreover, Zhang et al. [44] verified that CKD was associated with a reduction in left ventricular function and strain based on cardiac magnetic resonance imaging in patients with type $2 \mathrm{DM}$. Variability in eGFR might be associated with left ventricular dysfunction, which is predictive of all-cause mortality [45].

Albuminuria is associated with a rapid eGFR decline in patients with type $2 \mathrm{DM}[46,47]$. Moreover, UACR, rather than eGFR, is a significant predictor of mortality in patients with an eGFR $\geq 60 \mathrm{~mL} / \mathrm{min} / 1.73 \mathrm{~m}^{2}[7,15]$. On the other hand, an episode of acute kidney injury was also reported to significantly predict mortality after adjustment for albuminuria and CKD [28]. The prevalence of nonalbuminuric CKD has been increasing and is associated with long-term mortality in patients with DM $[48,49]$. According to our findings in the present study, variability in eGFR, independent of albuminuria, could be a significant predictor of all-cause mortality in type 2 DM patients with preserved renal function.

In the present study, there was no significant difference in all-cause mortality risk among the three slope types of eGFR changes. Even in the subgroup of patients with a high SD of eGFR, the slope of eGFR change was not significantly associated with mortality risk (the data are not shown). In line with our results, both inclining and declining eGFR slopes were associated with a higher all-cause mortality risk than a stable eGFR level in patients with stage 3A CKD [50]. Furthermore, there was no significant difference in mortality prediction ability between the index eGFR and the mean eGFR based on the C-index, IDI, and NRI in the present study. Therefore, an episode of kidney injury might have a long-term effect on mortality risk $[51,52]$.

In the present study, the HbA1c level was significantly associated with CKD at enrollment, but an HbA1c $\geq 7 \%$ was not an independent predictor for all-cause mortality. High HbA1c levels have been reported to be associated with CKD in patients with type 2 DM [53, 54]. However, intensive glucose control did not decrease all-cause mortality in a median 10-years follow-up in the United Kingdom Prospective Diabetes Study (UKPDS) [55]. Although the risk of all-cause mortality was reduced during an additional 10 years of the UKPDS posttrial observation [56], a baseline HbA1c $\geq 7 \%$ could not significantly predict mortality during a median follow-up of 19 months in the present study. Notably, the use of SGLT2 inhibitors was an independent protector against mortality in the 
present study. It has been reported that SGLT2 inhibitors have a glucose-independent benefit on mortality reduction, and protection occurred early in the EMPA-REG outcome trial [57]. In line with our study, Schechter et al. [58] reported that the use of SGLT2 inhibitors reduced all-cause mortality based on real-world practice data. It has been reported that the benefits of SGLT2 inhibitors depend on body weight based on the medical datasets from a multicenter health care system in Taiwan [59]. Furthermore, there are sex-specific effects of DM on mortality [60]. The effect of structured personal diabetes care on the reduction of all-cause mortality risk was worse in men than in women [61]. Consistently, male sex was an independent predictor for all-cause mortality in the present study.

There are several potential limitations that should be acknowledged in the present study. First, we collected only annual eGFR data instead of all available eGFR data. The advantage of using annual eGFR is that it is compatible with clinical practice, and the similar interval between the four eGFR data points prevents the effects of frequent measurements on SD. However, some episodes of short-term eGFR alteration might have been missed in the present study. Second, we used the MDRD equation for eGFR because the data were automatically calculated in our hospital information system. The Cockcroft and Gault (C-G) equation was reported to be more convincing for medicine-dose adjustment in the aged or female population [62]. However, the measurement of serum creatinine levels might occur several days earlier than the body-weight measurement for an outpatient interview, and we did not use the $\mathrm{C}-\mathrm{G}$ equation to avoid this time-lag induced bias. The MDRD equation has been reported to have the highest accuracy for measuring eGFR based on 24-h urine collection compared with the $\mathrm{C}-\mathrm{G}$ equation and the Chronic Kidney Disease Epidemiology Collaboration (CKD-EPI) equation among the population with DM [63]. Although the CKD-EPI equation has been reported to be better in mortality prediction than the MDRD equation in patients with type 2 DM [64], there is no consensus on the use of the CKDEPI equations which should be modified for application in Chinese population [65]. Furthermore, the use of the CKD-EPI equation is still not validated in eGFR variability, which might be increased due to the use of different formulae if serum creatinine varies across $0.7 \mathrm{mg} / \mathrm{dL}$ in females and $0.9 \mathrm{mg} / \mathrm{dL}$ in males [65]. Third, we did not exclude patients who began to use ACE inhibitors, ARBs, or SGLT2 inhibitors during the period of annual eGFR data collection. These medications may cause transient reduction in eGFR values. Fourth, we did not directly investigate the mechanisms or potential comorbidities associated with eGFR variability and mortality. Finally, this was an observational study that used retrospectively collected annual eGFR data. We did not investigate the effect of any specific intervention on eGFR variability and mortality. Our results cannot indicate that mortality will be reduced by decreasing eGFR variability.

\section{Conclusion}

In the present study, we found a synergistic effect of CKD and previous eGFR variability on all-cause mortality in patients with type $2 \mathrm{DM}$. In addition, the SD of annual eGFR might be an independent predictor of mortality in patients with preserved renal function (eGFR $\geq 60 \mathrm{~mL} / \mathrm{min} / 1.73 \mathrm{~m}^{2}$ ), but single-measured eGFR was not a significant predictor of mortality in patients with low eGFR variability after adjustment for the associated factors. This observational cohort study indicates a possible linkage between eGFR variability and long-term mortality; further large-scale studies regarding interventions to reduce eGFR variability to prevent mortality are warranted.

\begin{abstract}
Abbreviations
ACE: Angiotensin-converting enzyme; ARB: Angiotensin II receptor antagonists; BMI: Body mass index; C-G: Cockcroft and Gault; CKD: Chronic kidney disease; CKD-EPI: Chronic Kidney Disease Epidemiology Collaboration; Cl: Confidence interval; CVD: Cardiovascular disease; DM: Diabetes mellitus; eGFR: Estimated glomerular filtration rate; HbA1c: Hemoglobin A1c; HDL: Highdensity lipoprotein; HR: Hazard ratio; IDI: Integrated discrimination improvement; NRI: Net reclassification improvement; PAD: Peripheral artery disease; SD: Standard deviation; SGLT2: Sodium glucose cotransporter 2; UACR: Urinary albumin-to-creatinine ratio; UKPDS: United Kingdom Prospective Diabetes Study.
\end{abstract}

\section{Supplementary Information}

The online version contains supplementary material available at https://doi. org/10.1186/s12933-021-01399-z.

Additional file 1: Table S1. The baseline characteristics and mortality cause of expired patients categorized based on CKD and SD of eGFR.

Acknowledgements

Statistical analysis was performed by the Biostatistics Task Force of Taichung Veterans General Hospital

\begin{abstract}
Authors' contributions
YC contributed to data interpretation and the writing of the manuscript. YL contributed to data interpretation. IL contributed to the study design, data collection, data interpretation, and manuscript revision. IL, the guarantor of this work, had full access to all the data in the study and takes responsibility for the integrity of the data and the accuracy of the data analysis. All authors read and approved the final manuscript.
\end{abstract}

\section{Funding}

This work was supported by grants from the Taichung Veterans General Hospital, Taiwan (Grant Number TCVGH-1103503C), the National Health Research Institute (Grant Number NHRI-EX110-10927HT), and the Ministry of Science and Technology, Taiwan (Grant Number MOST 110-2314-B-075A-004-MY3). The funding bodies had no role in the decision to submit the manuscript for publication. 


\section{Availability of data and materials}

The datasets used and/or analyzed during the current study are available from the corresponding author on reasonable request.

\section{Declarations}

\section{Ethics approval and consent to participate}

The study complied with the Declaration of Helsinki and was approved by the Institutional Review Board of Taichung Veterans General Hospital, with the need for informed consent waived.

\section{Consent for publication}

Not applicable.

\section{Competing interests}

The authors declare that they have no competing interests.

\section{Author details}

${ }^{1}$ Division of Endocrinology and Metabolism, Department of Internal Medicine, Taichung Veterans General Hospital, No. 1650, Section 4, Taiwan Boulevard, Taichung 40705, Taiwan. ${ }^{2}$ School of Medicine, Chung Shan Medical University, Taichung City 40201, Taiwan. ${ }^{3}$ Department of Computer Science and Information Engineering, National Taiwan University, Taipei 10617, Taiwan. ${ }^{4}$ School of Medicine, National Yang Ming Chiao Tung University, Taipei 11221, Taiwan.

\section{Received: 24 August 2021 Accepted: 8 October 2021}

Published online: 18 October 2021

\section{References}

1. Go AS, Chertow GM, Fan D, McCulloch CE, Hsu CY. Chronic kidney disease and the risks of death, cardiovascular events, and hospitalization. N Engl J Med. 2004;351(13):1296-305.

2. GBD Chronic Kidney Disease Collaboration. Global, regional, and national burden of chronic kidney disease, 1990-2017: a systematic analysis for the Global Burden of Disease Study 2017. Lancet. 2020:395(10225):709-33.

3. Hill NR, Fatoba ST, Oke JL, Hirst JA, O'Callaghan CA, Lasserson DS, Hobbs FD. Global prevalence of chronic kidney disease - a systematic review and meta-analysis. PLOS ONE. 2016;11(7): e0158765.

4. Saeedi P, Petersohn I, Salpea P, Malanda B, Karuranga S, Unwin N, Colagiuri S, Guariguata L, Motala AA, Ogurtsova K, et al. Global and regional diabetes prevalence estimates for 2019 and projections for 2030 and 2045: results from the International Diabetes Federation Diabetes Atlas, 9(th) edition. Diabetes Res Clin Pract. 2019;157: 107843.

5. Thomas MC, Cooper ME, Zimmet P. Changing epidemiology of type 2 diabetes mellitus and associated chronic kidney disease. Nat Rev Nephrol. 2016;12(2):73-81.

6. Deng Y, Li N, Wu Y, Wang M, Yang S, Zheng Y, Deng X, Xiang D, Zhu Y, Xu $P$, et al. global, regional, and national burden of diabetes-related chronic kidney disease from 1990 to 2019. Front Endocrinol. 2021;12: 672350.

7. Afkarian M, Sachs MC, Kestenbaum B, Hirsch IB, Tuttle KR, Himmelfarb J, de Boer $\mathrm{H}$. Kidney disease and increased mortality risk in type 2 diabetes. J Am Soc Nephrol. 2013;24(2):302-8.

8. Salinero-Fort MA, Andres-Rebollo FJS, de Burgos-Lunar C, AbanadesHerranz JC, Carrillo-de-Santa-Pau E, Chico-Moraleja RM, Jimenez-Garcia R, Lopez-de-Andres A, Gomez-Campelo P, Group M. Cardiovascular and all-cause mortality in patients with type 2 diabetes mellitus in the MADIABETES Cohort Study: association with chronic kidney disease. J Diabetes Complications. 2016;30(2):227-36.

9. Penno G, Solini A, Bonora E, Orsi E, Fondelli C, Zerbini G, Trevisan R, Vedovato $M$, Cavalot F, Laviola L, et al. Defining the contribution of chronic kidney disease to all-cause mortality in patients with type 2 diabetes: the Renal Insufficiency And Cardiovascular Events (RIACE) Italian Multicenter Study. Acta Diabetol. 2018;55(6):603-12.

10. American Diabetes Association. 11. Microvascular complications and foot care: standards of medical care in diabetes-2021. Diabetes Care 2021:44(Suppl 1):S151-67.
11. Liew A, Bavanandan S, Prasad N, Wong MG, Chang JM, Eiam-Ong S, Hao CM, Lim CY, Lim SK, Oh KH, et al. Asian pacific society of nephrology clinical practice guideline on diabetic kidney disease - an executive summary. Nephrology. 2020;25(11):809-17.

12. Taiwan DAOTROC. Executive summary of the DAROC clinical practice guidelines for diabetes care-2018. J Formos Med Assoc. 2020;119(2):577-86.

13. Inker LA, Astor BC, Fox CH, Isakova T, Lash JP, Peralta CA, Kurella Tamura M, Feldman HI. KDOQI US commentary on the 2012 KDIGO clinical practice guideline for the evaluation and management of CKD. Am J Kidney Dis. 2014:63(5):713-35.

14. Stevens LA, Coresh J, Greene T, Levey AS. Assessing kidney function-measured and estimated glomerular filtration rate. N Engl J Med. 2006:354(23):2473-83.

15. Chronic Kidney Disease Prognosis C, Matsushita K, van der Velde M, Astor BC, Woodward M, Levey AS, de Jong PE, Coresh J, Gansevoort RT. Association of estimated glomerular filtration rate and albuminuria with all-cause and cardiovascular mortality in general population cohorts: a collaborative meta-analysis. Lancet. 2010;375(9731):2073-81.

16. Luo Y, Wang X, Wang Y, Wang C, Wang H, Wang D, Liu L, Jia Q, Liu G, Zhao $X$, et al. Association of glomerular filtration rate with outcomes of acute stroke in type 2 diabetic patients: results from the China National Stroke Registry. Diabetes Care. 2014;37(1):173-9.

17. Penno G, Orsi E, Solini A, Bonora E, Fondelli C, Trevisan R, Vedovato M, Cavalot F, Gruden G, Laviola L, et al. Renal hyperfiltration is independently associated with increased all-cause mortality in individuals with type 2 diabetes: a prospective cohort study. BMJ Open Diabetes Res Care. 2020. https://doi.org/10.1136/bmjdrc-2020-001481.

18. Folkerts K, Petruski-Ivleva N, Comerford E, Blankenburg M, Evers T, Gay A, Fried L, Kovesdy CP. Adherence to chronic kidney disease screening guidelines among patients with type 2 diabetes in a US administrative claims database. Mayo Clin Proc. 2021;96(4):975-86.

19. Wang CY, Wu YL, Sheu WH, Tu ST, Hsu CC, Tai TY. Accountability and utilization of diabetes care from 2005 to 2014 in Taiwan. J Formos Med Assoc. 2019;118(Suppl 2):S111-21.

20. Lee YB, Kim DH, Roh E, Hong SH, Kim JA, Yoo HJ, Baik SH, Han K, Choi KM. Variability in estimated glomerular filtration rate and the incidence of type 2 diabetes: a nationwide population-based study. BMJ Open Diabetes Res Care. 2020. https://doi.org/10.1136/bmjdrc-2020-001187.

21. Tseng CL, Lafrance JP, Lu SE, Soroka O, Miller DR, Maney M, Pogach LM. Variability in estimated glomerular filtration rate values is a risk factor in chronic kidney disease progression among patients with diabetes. BMC Nephrol. 2015;16:34.

22. Perkins RM, Tang X, Bengier AC, Kirchner HL, Bucaloiu ID. Variability in estimated glomerular filtration rate is an independent risk factor for death among patients with stage 3 chronic kidney disease. Kidney Int. 2012;82(12):1332-8

23. Jun M, Harris K, Heerspink HJL, Badve SV, Jardine MJ, Harrap S, Hamet P, Marre M, Poulter N, Kotwal S, et al. Variability in estimated glomerular filtration rate and the risk of major clinical outcomes in diabetes: post hoc analysis from the ADVANCE trial. Diabetes Obes Metab. 2021;23(6):1420-5.

24. Pan WH, Flegal KM, Chang HY, Yeh WT, Yeh CJ, Lee WC. Body mass index and obesity-related metabolic disorders in Taiwanese and US whites and blacks: implications for definitions of overweight and obesity for Asians. Am J Clin Nutr. 2004;79(1):31-9.

25. Huang KC. Obesity and its related diseases in Taiwan. Obes Rev. 2008;9(Suppl 1):32-4.

26. Al-Aly Z, Balasubramanian S, McDonald JR, Scherrer JF, O'Hare AM. Greater variability in kidney function is associated with an increased risk of death. Kidney Int. 2012;82(11):1208-14.

27. Davis TM, Chubb SA, Davis WA. The relationship between estimated glomerular filtration rate trajectory and all-cause mortality in type 2 diabetes: the Fremantle Diabetes Study. Eur J Endocrinol. 2016;175(4):273-85.

28. Monseu M, Gand E, Saulnier PJ, Ragot S, Piguel X, Zaoui P, Rigalleau V, Marechaud R, Roussel R, Hadjadj S, et al. Acute kidney injury predicts major adverse outcomes in diabetes: synergic impact with low glomerular filtration rate and albuminuria. Diabetes Care. 2015;38(12):2333-40.

29. Kelly KJ, Williams WW Jr, Colvin RB, Meehan SM, Springer TA, GutierrezRamos JC, Bonventre JV. Intercellular adhesion molecule-1-deficient mice are protected against ischemic renal injury. J Clin Invest. 1996;97(4):1056-63. 
30. Kelly KJ. Distant effects of experimental renal ischemia/reperfusion injury. J Am Soc Nephrol. 2003;14(6):1549-58.

31. Weil EJ, Kobes S, Jones LI, Hanson RL. Glycemia affects glomerular filtration rate in people with type 2 diabetes. BMC Nephrol. 2019;20(1):397.

32. Monnier L, Mas E, Ginet C, Michel F, Villon L, Cristol JP, Colette C. Activation of oxidative stress by acute glucose fluctuations compared with sustained chronic hyperglycemia in patients with type 2 diabetes. JAMA. 2006;295(14):1681-7.

33. Ceriello A, Esposito K, Piconi L, Ihnat MA, Thorpe JE, Testa R, Boemi M, Giugliano D. Oscillating glucose is more deleterious to endothelial function and oxidative stress than mean glucose in normal and type 2 diabetic patients. Diabetes. 2008;57(5):1349-54.

34. Brownlee M. The pathobiology of diabetic complications: a unifying mechanism. Diabetes. 2005;54(6):1615-25.

35. Muggeo M, Zoppini G, Bonora E, Brun E, Bonadonna RC, Moghetti P, Verlato G. Fasting plasma glucose variability predicts 10-year survival of type 2 diabetic patients: the Verona Diabetes Study. Diabetes Care. 2000;23(1):45-50.

36. Tonelli M, Wiebe N, Guthrie B, James MT, Quan H, Fortin M, Klarenbach SW, Sargious P, Straus S, Lewanczuk R, et al. Comorbidity as a driver of adverse outcomes in people with chronic kidney disease. Kidney Int. 2015;88(4):859-66.

37. Yokoyama H, Kanno S, Takahashi S, Yamada D, Itoh H, Saito K, Sone H, Haneda M. Determinants of decline in glomerular filtration rate in nonproteinuric subjects with or without diabetes and hypertension. Clin J Am Soc Nephrol. 2009:4(9):1432-40.

38. van Bommel EJM, Ruiter D, Muskiet MHA, van Baar MJB, Kramer MHH, Nieuwdorp M, Joles JA, Bjornstad P, van Raalte DH. Insulin sensitivity and renal hemodynamic function in metformin-treated adults with type 2 diabetes and preserved renal function. Diabetes Care. 2020;43(1):228-34.

39. Penno G, Solini A, Orsi E, Bonora E, Fondelli C, Trevisan R, Vedovato M, Cavalot F, Zerbini G, Lamacchia O, et al. Insulin resistance, diabetic kidney disease, and all-cause mortality in individuals with type 2 diabetes: a prospective cohort study. BMC Med. 2021;19(1):66.

40. Zhang X, Kumari N, Low S, Ang K, Yeo D, Yeoh LY, Liu A, Kwan PY, Tang WE, Tavintharan $\mathrm{S}$, et al. The association of serum creatinine and estimated glomerular filtration rate variability with diabetic retinopathy in Asians with type 2 diabetes: a nested case-control study. Diab Vasc Dis Res. 2018;15(6):548-58

41. Hsieh YM, Lee WJ, Sheu WH, LiYH, Lin SY, Lee IT. Inpatient screening for albuminuria and retinopathy to predict long-term mortality in type 2 diabetic patients: a retrospective cohort study. Diabetol Metab Syndr. 2017;9:29.

42. Matsushita K, Ballew SH, Coresh J, Arima H, Ärnlöv J, Cirillo M, Ebert N, Hiramoto JS, Kimm H, Shlipak MG, et al. Measures of chronic kidney disease and risk of incident peripheral artery disease: a collaborative meta-analysis of individual participant data. Lancet Diabetes Endocrinol. 2017;5(9):718-28. https://doi.org/10.1016/S2213-8587(17)30183-3.

43. LiYH, Sheu WH, Lee IT. Use of the ankle-brachial index combined with the percentage of mean arterial pressure at the ankle to improve prediction of all-cause mortality in type 2 diabetes mellitus: an observational study. Cardiovasc Diabetol. 2020;19(1):173

44. Zhang Y, Wang J, Ren Y, Yan WF, Jiang L, Li Y, Yang ZG. The additive effects of kidney dysfunction on left ventricular function and strain in type 2 diabetes mellitus patients verified by cardiac magnetic resonance imaging. Cardiovasc Diabetol. 2021;20(1):11.

45. Hein AM, Scialla JJ, Sun JL, Greene SJ, Shaw LK, Chiswell K, Pun PH, Mentz RJ. Estimated glomerular filtration rate variability in patients with heart failure and chronic kidney disease. J Card Fail. 2021;S1071-9164(21):00159-67.

46. Cid Ruzafa J, Paczkowski R, Boye KS, Di Tanna GL, Sheetz MJ, Donaldson R, Breyer MD, Neasham D, Voelker JR. Estimated glomerular filtration rate progression in UK primary care patients with type 2 diabetes and diabetic kidney disease: a retrospective cohort study. Int J Clin Pract. 2015;69(8):871-82.

47. Zoppini G, Targher G, Chonchol M, Ortalda V, Negri C, Stoico V, Bonora E. Predictors of estimated GFR decline in patients with type 2 diabetes and preserved kidney function. Clin J Am Soc Nephrol. 2012;7(3):401-8.

48. Afkarian M, Zelnick LR, Hall YN, Heagerty PJ, Tuttle K, Weiss NS, de Boer IH. Clinical manifestations of kidney disease among US adults with diabetes, 1988-2014. JAMA. 2016;316(6):602-10.

49. Penno G, Solini A, Orsi E, Bonora E, Fondelli C, Trevisan R, Vedovato M, Cavalot F, Lamacchia O, Scardapane M, et al. Non-albuminuric renal impairment is a strong predictor of mortality in individuals with type 2 diabetes: the Renal Insufficiency And Cardiovascular Events (RIACE) Italian multicentre study. Diabetologia. 2018;61(11):2277-89.

50. Xie Y, Bowe B, Xian H, Balasubramanian S, Al-Aly Z. Renal function trajectories in patients with prior improved eGFR slopes and risk of death. PLoS ONE. 2016;11(2): e0149283.

51. James MT, Hemmelgarn BR, Wiebe N, Pannu N, Manns BJ, Klarenbach SW, Tonelli M, Alberta Kidney Disease N. Glomerular filtration rate, proteinuria, and the incidence and consequences of acute kidney injury: a cohort study. Lancet. 2010;376(9758):2096-103.

52. Grams ME, Rabb H. The distant organ effects of acute kidney injury. Kidney Int. 2012:81(10):942-8.

53. Zoungas $S$, Arima H, Gerstein HC, Holman RR, Woodward M, Reaven $P$, Hayward RA, Craven T, Coleman RL, Chalmers J, Collaborators on Trials of Lowering Glucose (CONTROL) group. Effects of intensive glucose control on microvascular outcomes in patients with type 2 diabetes: a meta-analysis of individual participant data from randomised controlled trials. Lancet Diabetes Endocrinol. 2017:5(6):431-7.

54. Patel A, MacMahon S, Chalmers J, Neal B, Billot L, Woodward M, Marre M, Cooper M, Glasziou P, Grobbee D, et al. Intensive blood glucose control and vascular outcomes in patients with type 2 diabetes. N Engl I Med. 2008;358(24):2560-72.

55. UK Prospective Diabetes Study (UKPDS) Group. Intensive blood-glucose control with sulphonylureas or insulin compared with conventional treatment and risk of complications in patients with type 2 diabetes (UKPDS 33). Lancet. 1998;352(9131):837-53.

56. Holman RR, Paul SK, Bethel MA, Matthews DR, Neil HA. 10-year followup of intensive glucose control in type 2 diabetes. N Engl $J$ Med. 2008;359(15):1577-89.

57. Zinman B, Wanner C, Lachin JM, Fitchett D, Bluhmki E, Hantel S, Mattheus M, Devins T, Johansen OE, Woerle HJ, et al. Empagliflozin, cardiovascular outcomes, and mortality in type 2 diabetes. N Engl J Med. 2015;373(22):2117-28.

58. Schechter M, Melzer-Cohen C, Rozenberg A, Yanuv I, Chodick G, Karasik A, Kosiborod M, Mosenzon O. Cardiorenal outcomes with sodium/glucose cotransporter-2 inhibitors in patients with type 2 diabetes and low kidney risk: real world evidence. Cardiovasc Diabetol. 2021;20(1):169.

59. Chan YH, Chen SW, Chao TF, Kao YW, Huang CY, Chu PH. The risk of consequent nephropathy following initial weight loss in diabetic patients treated with sodium glucose cotransporter 2 inhibitors. Cardiovasc Diabetol. 2021;20(1):167.

60. Damsgaard EM, Frøland A, Mogensen CE. Over-mortality as related to age and gender in patients with established non-insulin-dependent diabetes mellitus. J Diabetes Complications. 1997;11(2):77-82.

61. Krag MØ, Hasselbalch L, Siersma V, Nielsen AB, Reventlow S, Malterud K, de Fine ON. The impact of gender on the long-term morbidity and mortality of patients with type 2 diabetes receiving structured personal care: a 13 year follow-up study. Diabetologia. 2016;59(2):275-85.

62. Chudek J, Kolonko A, Owczarek AJ, Wieczorowska-Tobis K, Broczek K, Skalska $A$, Więcek A. Clinical factors increasing discrepancies of renal function assessment with MDRD and Cockcroft-Gault equations in old individuals. Eur Geriatr Med. 2018;9(5):713-20.

63. Schwandt A, Denkinger M, Fasching P, Pfeifer M, Wagner C, Weiland J, Zeyfang A, Holl RW. Comparison of MDRD, CKD-EPI, and Cockcroft-Gault equation in relation to measured glomerular filtration rate among a large cohort with diabetes. J Diabetes Complications. 2017;31(9):1376-83.

64. Targher G, Zoppini G, Mantovani W, Chonchol M, Negri C, Stoico V, Mantovani A, De Santi F, Bonora E. Comparison of two creatinine-based estimating equations in predicting all-cause and cardiovascular mortality in patients with type 2 diabetes. Diabetes Care. 2012;35(11):2347-53.

65. Lee CH, Shih AZL, Woo YC, Fong CHY, Yuen MMA, Chow WS, Lam KSL. Which creatinine-based estimated glomerular filtration rate equation best predicts all-cause mortality in Chinese subjects with type 2 diabetes? Diabetes Res Clin Pract. 2017;126:25-9.

\section{Publisher's Note}

Springer Nature remains neutral with regard to jurisdictional claims in published maps and institutional affiliations. 